\title{
An ICT-Based Agricultural Extension Service Delivery for Nigeria
}

Durojaiye, L. O. ${ }^{1}$, Abubakar, S. Z ${ }^{1}$, Omeneza, Z. $E^{1}$, Muhammed, $\mathbf{S}^{1}$, Wahab, A. A ${ }^{1}$, Ismail, F.O' and Musa, R.A.

${ }^{1}$ National Agricultural Extension and Research Liaison Services, Ahmadu Bello University, Zaria

${ }^{2}$ KITS Technologies, No. 100, Zoo Road, Kano.

Corresponding author: durojaiyeluqman@yahoo.com Telephone: +2348062568159

\begin{abstract}
This paper proposed an ICT-based extension service delivery for Nigeria. The proposed design, though to be use as supplement to the existing system would engender an extension delivery system that is void of many of the limitations inherent in the earlier approaches. Basically, it revolves round the use ICT facilities like VSAT, Routers/Switches, PCs, Radio/Antennae, etc. to provide agricultural information through the internet. Farmers in the remotest rural villages in Nigeria can communicate with extension workers without having to meet face to face with them; an integral aspect of many of the traditional approaches. The communication provided by the Internet can be real time voiced communication, video conferencing, chats, etc. or pre-recorded data in the form of texts (mail), audio or audio-visuals which can be used to provide training/instruction/guidance to farmers about farm activities. This would go a long way to enhance the government's agricultural transformation agenda (ATA) as it has the potential to ensure the inclusion of more rural farmers. The design, once deployed, is almost self sustainable.
\end{abstract}

Key words: ICT, Internet, Agricultural Information, Traditional Extension Approach.

\section{Introduction}

According to http://www.unescobkk.org/index.php?id=1013 in Adebayo and Adesope (2007), ICT is defined as the term used to describe the tools and processes to access, retrieve, store, organize, manipulate, produce, present and exchange information by electronic and other automated means. These include hardware, software and telecommunications in the forms of personal computers, scanners, digital cameras, handhelds/PDAs, phones, faxes, modems, CD and DVD players and recorders, digitalized video, radio and TV and programmes like database systems and multimedia applications. Kwadwo and Daniel, (2012) argues that "the advent of personal computers, the internet and mobile telephone during the last two decades has provided a much wider choice in collection, storage, processing, transmission and presentation of information in multiple formats to meet the diverse requirement and skills of people". This paper looks at the use of ICT to augment extension work in such a way that the barrier occasioned by remote/long distance between extension agents and farmers and the "face to face" meeting between farmers and extension agents can be drastically reduced; such that even farmers in the farthest and remotest rural villages can communicate with extension workers; thereby minimizing the overhead cost incurred by extension agents due to travelling. Again, the usual problem associated with the top to bottom nature of earlier approaches; extension agent-driven nature of current services; where the extension agents determine everything; what to farm and what not to farm, when to visit and when not to visit, etc would be addressed. With the proposed design, farmers can initiate requests, make observations and receive real time or pre-recorded responses/materials (in the form of text, images/photos, audio, audio-visuals etc.) via the internet at a facility provided in the community where they farm (or even at the convenience of their homes or farms). 


\section{The ICT-Based Agricultural Extension Service Delivery (IAESD)}

Recognizing the realities of typical villages, the IAESD design is summarized as follows. It is essentially the creation of an ICT-enabled agriculture centre (IAC) in village(s) (e.g. adopted villages) where extension service is required. The IAC is a structure/building that houses all the ICT facilities that makes communication between it and the outside world possible. The IAC uses the popular internet to provide wireless communication between farmers/rural communities and extension agents/centers, other farmers (within and outside the community) etc. With a good internet bandwidth (1by1Mbps), IP based multi-cast applications like audio and video streaming between extension agents/centers and farmers/IAC is possible. Farmers at a particular IAC can also share resources and information with other farmers anywhere on the globe. Figure 1 shows a cluster of IACs and an extension center.

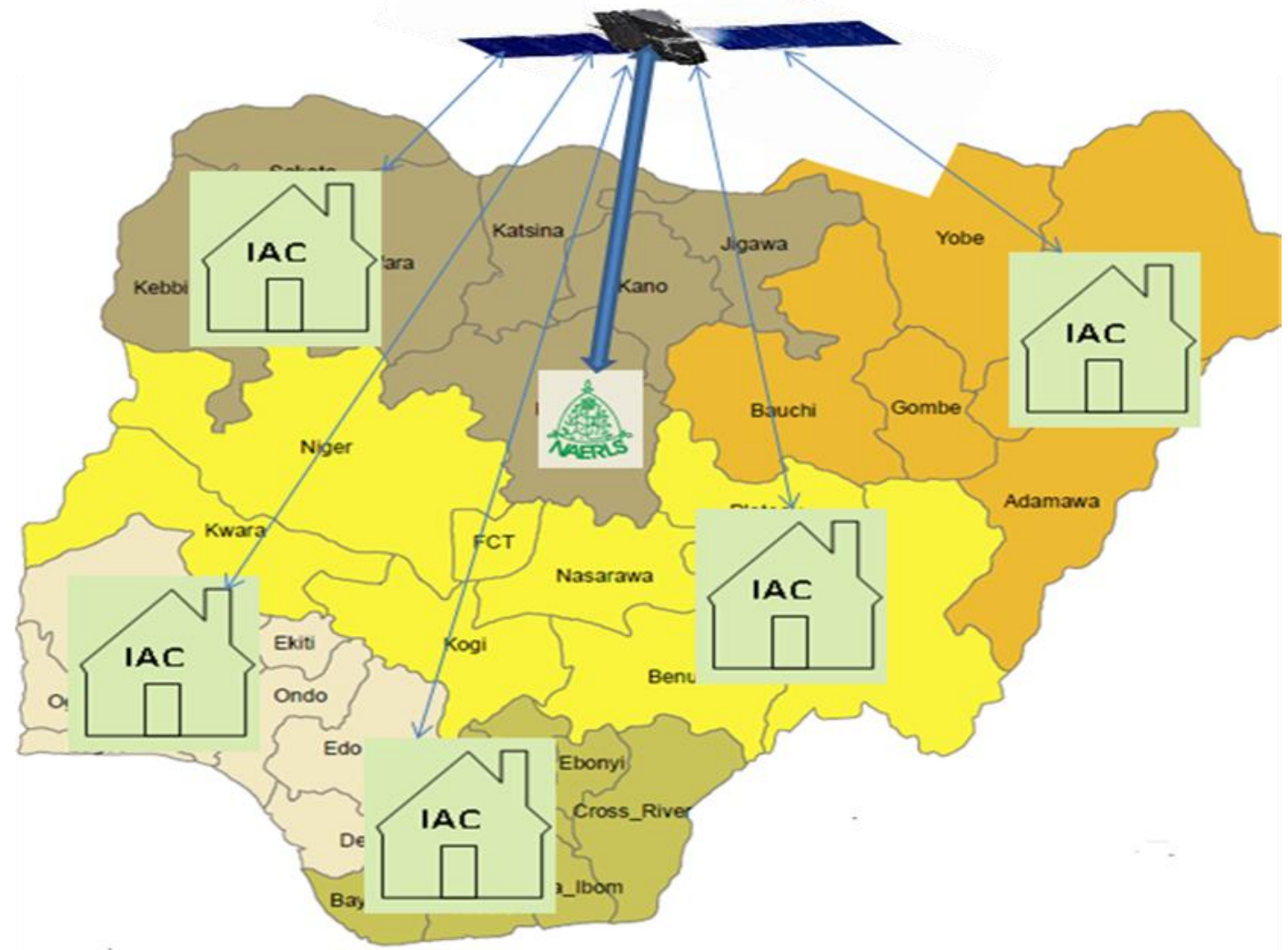

Figure 1. IACs in the proposed IAESD

Major ICT facilities required at an IAC

Some of the items required to enable an IAC performs its full functionalities are illustrated in table 1. 
Table 1: Items in an IAC

\begin{tabular}{lllll}
\hline S/N & \multicolumn{1}{c}{ ITEM } & \multicolumn{1}{c}{ Quantity } & \multicolumn{1}{c}{ Cost } & \multicolumn{1}{c}{ Remarks } \\
\hline 1 & Building & & & \\
1 & VSAT Equipment & 1 & $\mathrm{~N} 450,000$ & C-Band Prepared \\
2 & Projector & 1 & $\mathrm{~N} 90,000$ & \\
3 & Laptop & 1 & $\mathrm{~N} 125,000$ & \\
4 & Solar Power Backup & 1 Set of 5KVA & $\mathrm{N} 1,200,000$ & \\
5 & Desktop Computer & 1 & $\mathrm{~N} 90,000$ & \\
6 & Air Condition & 1 & $\mathrm{~N} 65,000$ & \\
7 & PBX \& VOIP(Hybrid) & 1 & $\mathrm{~N} 260,000$ & \\
8 & IP Cameras & 2 & $\mathrm{~N} 32,000 * 2$ & \\
9 & Microphone & 1 & $\mathrm{~N} 3,000$ & \\
10 & Smart phone & 1 & $\mathrm{~N} 140,000$ & \\
11 & Flat Screen TV & 1 & $\mathrm{~N} 160,000$ & \\
12 & Router & 1 & $\mathrm{~N} 20,500$ & \\
13 & Switch & 1 & & \\
14 & $* *$ Internet Bandwidth & $(1$ by1Mbps) & & \\
& & & & \\
\hline
\end{tabular}

*Depends on the capacity of the benefitting community; it can be a building/container etc.

${ }^{* *}$ This can be obtained free (or at a token fee) see section 3.2

***Estimates made in February, 2013.

\section{Opportunities offered by the Proposed Design}

A well structured ICT center or IAC has the potential to help farmers have access to regular information, guidance, and help from a variety of sources; the extension agents, fellow famers (within and outside their communities), agricultural database websites to mention a few. As shown in Figure 2, requests are made to the extension agent centre and they in turn get appropriate, up-to-date and validated responses from relevant researchers as different from the traditional approach or the "help line" (Mahruk, 2011) where all queries are managed by one agricultural expert. 


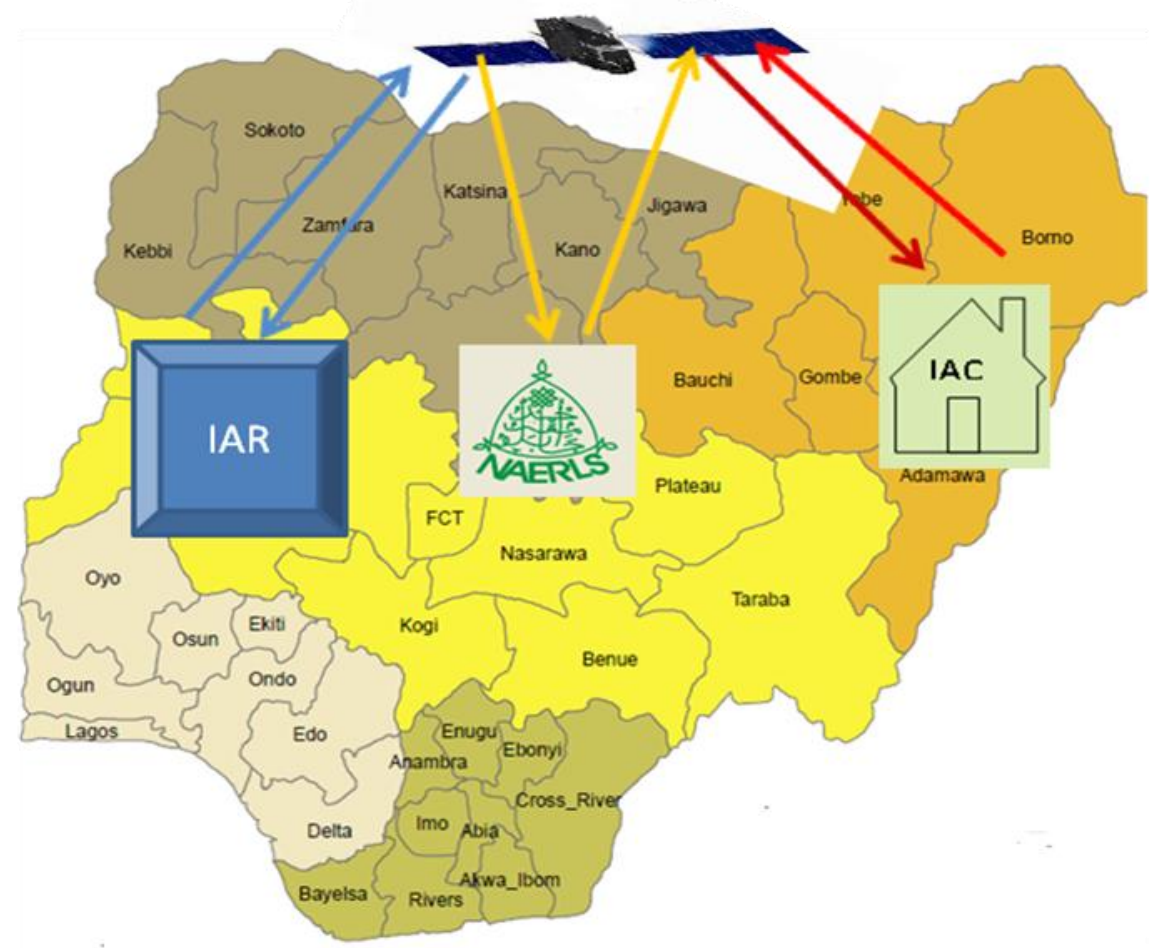

Information/request sent/received from Extension Agents by IAR Information/request sent/received from IAC/IAR by NAERLS Information/request sent/received from NAERLS by IAC

Figure 2. Communication between an IAC, Extension Center (e.g. NAERLS) and a Research Institute (e.g. IAR)

\section{Unlimited access to information}

Another attractive feature of this arrangement is the fact that, it will stimulate farmers driven extension; one in which farmers request for guidance and assistance based on their unique needs. Again, farmers do not have to wait for extension agents to visit them before they can make requests; the demands can be made almost immediately when there is need for it, as the internet provided by VSAT technology is thought to have up-times in the magnitude of 99.5\% and above, such that mission critical applications like Bank ATM's, Navy and Point of Sale appliances use it (Bavota, 2013).

\section{Cost effectiveness}

Another advantage of the proposed design is its cost effectiveness. The cost of setting up VSAT site is rapidly going down by the day. Thanks to the comparatively cheap cost of deploying a VSAT site (compared to cable or fiber optic terrestrial alternative) on one hand and the general fall in prices of electronics on the other. Furthermore, the rural people in Nigeria stand a chance of getting internet service at a reduced rate or even free of charge! 
This is because, at the moment (2013), there is a federal government policy implemented via the Nigerian Government-owned internet service provider; Galaxy Backbone Plc, located in Abuja. According to the company, one of its mandates is "Provide connectivity and internet access to rural and underserved communities..."

(http://www.galaxybackbone.com/about.php)

\section{VSAT networks over terrestrial alternatives}

Communication networks can be broadly divided into two: Terrestrial and Satellite networks. Satellite networks are based on the Very Small Aperture Terminal (VSAT) technology. The VSAT technology comprises of three main components: orbiting Satellite, Central Hub (With a Big Dish Antenna) and a number of smaller nodes (smaller dish antenna) kept at various remote locations where communication is required. Bavota, (2013) observed that the VSAT has a number of advantages over the terrestrial alternatives, three of which are relevant to its choice in this paper. Firstly, is its suitability for remote location (rural areas, ships and coastal regions, hills, etc.) deployment; a reality of villages not just in Nigeria, but all over the world. Secondly, is the high efficiency in handling latency sensitive applications like voice and video applications; an important ingredient that makes the intervention suitable for less educated people in the rural areas. Lastly, the running cost (site/location setup and ongoing subscription) is rapidly going down. The advantage here is that, the IAC can be maintained with little amount of money that benefitting farmers/communities can afford.

\section{Challenges}

In this part of the paper, we highlight drawbacks of the proposed design and discuss how their effects can be minimized.

\section{Illiteracy}

Often times, illiteracy has played no small role in making technology adoption difficult. This is particularly true when the technology has to do with information exchange. For example, the numbers of people that uses voice communication on their mobile phone is usually more than those who use the mobile phone's text messaging functionality. This reality for example informed recent developments such as Spoken Web; which essentially is a voice driven eco-system parallel and complementary to that of the existing World Wide Web (ACM SIGCOMM, 2007) so that the underserved and illiterate population can have access to information on "Voice sites" (and not websites) in audio format. Similarly, this intervention is meant to target an audience that is usually less educated; the rural people. Therefore, an appropriate model must be able to transmit and exchange all forms of digital messages; text, voice/audio, pictures/images, video/audio-visuals etc. The advantage here is that whatever the level of education of the farmer, he can access information.

\section{Power supply requirement of the IAC}

Just like other electronic gadgets, all ICT tools/facilities require electricity to function. However, as observed earlier in this paper, the target environment is usually not with regular supply of electricity. Thus, this model suggests hybrid power supply system; it makes use of supply from the grid (if available) and uses the "stored" energy provided by deep cycle battery banks in the absence of a grid supply. A combination of solar panels is also required for charging and supplying during the day. During the nights, when the sun is no longer present, the battery alternative is in use. A device referred to as inverter is used to convert the $d c$ nature of solar and battery power into the ac supply required by the ICT facilities. 


\section{Funding}

The funding required for this model can be divided into two; the set up cost and the recurring/overhead/maintenance of an IAC. The former can be provided by a collaboration of farmers, sponsors and or local government councils of the benefitting farming community. The latter consists majorly of internet subscription cost which can be obtained free of charge (see 3.2 above). Another is the remunerations of the personnel ( 2 at maximum) that maintain the operations of the IAC. We suggest that youths/farmers/NYSC Corp members in the benefitting communities be trained on how to use the facilities of the IAC. This would further help to reduce overhead/running cost.

\section{Conclusion and Recommendation}

This model will no doubt help the extension workers reach more farmers in a cost effective way. To achieve this, the following recommendations are made;

1. This design should be further examined and fine-tuned for improvement.

2. Stakeholders in the agricultural (particularly the rural farmers) should be intimated about the benefits of the model.

3. Pilot sites ( 2 or 3 ) be set up in different locations (e.g. in the Northern and Southern part of the country) to evaluate its effectiveness.

4. Recommendations for further improvement based on the outcomes in (3) above be made.

5. Sensitization for sponsorship purposes should be undertaken. Potential Sponsors/donor and Government agencies should be mobilized in this direction.

6. The experience should be duplicated in as many farming communities as possible.

\section{Summary}

In the light of the reality on ground in Nigeria as pointed above, an extension delivery system that utilizes internet for the exchange of information between extension agents and farmers is the right step in the right direction. This step is particularly relevant now as there is some genuine attempt at reaching more farmers in the rural areas through ATA. Thus, this proposed design should be adopted if we truly desire not just a robust but equally sustainable agricultural extension delivery system in Nigeria.

\section{References}

Adebayo E. and Adesope O. (2007). Awareness, access and usage of information and communication technologies between female researchers and extensionists, International Journal of Education and Development using Information and Communication Technology. (3). (1). pp. 85-93.

Asenso-Okyere, K. and Ayalew-Mekonnen, D. (2012). The Importance of ICTs in the Provision of Information for Improving Agricultural Productivity and Rural Incomes in Africa. African Human Development Report. UNDP Sponsored research Series.

Bovota C. (2012). Advantages of VSAT - Why Satellite Networks make a good choice for WAN and Internet connectivity. Available at http://www.excitingip.com/806/vsatbenefits-advantages-for-wide-area-networks-and-broadband/

Rural and urban Development Case study-Nigeria (2004). DFID, UK Department for International Development. Oxford Policy Statement. Available online at: http: www.passlivelihoods.org.uk/site sitefiles\%5Creports\%5Cproject id 167\%5CNigeria 
\%20Rural\%20Urban\%20Change\%20Case\%20Study RU0173.pdf. Retrieved: 09-32013.

http://countrystudies.us/nigeria/57.htm

Mahrukh S. (2011). A model for ICT based services for agriculture extension in Pakistan. CABI Ref.: FR/CABI-PK/KR10015/2026. Available at http://r4d.dfid.gov.uk/PDF/Outputs/Misc Infocomm/60818-extensionmodelPakistan.pdf. Retrieved: 08-02-2013.

Moyosola, O. A (2004). Rural Urban Migration and Productivity in the Nigerian Agricultural Sector. Masters thesis submitted to the Simon Fraser University.

Olomola, A. S. (2007). Strategies for Managing the Opportunities and Challenges of the Current Agricultural Commodity Booms in Sub Saharan Africa. Seminar Papers on Managing Commodity Booms in Sub-Saharan Africa: A Publication of the AERC Senior Policy Seminar IX. African Economic Research Consortium (AERC), Nairobi, Kenya

Technical Centre for Agricultural and Rural Cooperation (CTA), (2006). ICTs Transforming Agricultural Extension? Report of the 6th Consultative Expert Meeting of CTA's Observatory on ICTs. CTA Working Document Number 8034. The ACP-EU Technical Centre for Agricultural and Rural Cooperation (CTA). Pp. 5\&8.

Ukpe E. and Chukwurah J., 2012. Information \& Communication Technology (ICT) for Agricultural Development in Rural Nigeria Journal of information and communication technologies, volume 2, issue 2, February 2012.

WWTW: The World Wide Telecom Web (2007). Proceedings of ACM SIGCOMM Workshop on Networked Systems for Developing Regions (NSDR), August 2007, Kyoto, Japan.

Xiaolan F. and Shaheen A. 2012. Impact of Mobile Telephone on the Quality and Speed of Agricultural Extension Services Delivery: Evidence from the Rural e-services Project in India. Paper presented at the International Association of Agricultural Economists (IAAE). Triennial Conference, Foz do Iguaçu, Brazil. 